\title{
Livros, cadernos e papéis avulsos: estudo filológico de um inventário do cartório e do arquivo da Câmara de Santana de Parnaíba (1764)
}

DOI: http://dx.doi.org/10.21165/el.v50i2.2895

Ivan Douglas de Souza ${ }^{1}$

\section{Resumo}

Este trabalho tem como objetivo apresentar o estudo filológico de um termo registrado no "Livro de Actas 1757 a 1764" da Vila de Santana de Parnaíba, intitulado "Termo de emtregua do Cartorio desta villa [...]". De fato, tal documento, escrito em 12 de janeiro de 1764, funciona como um inventário, pois contém listas de maços de papéis avulsos e de livros produzidos e/ou guardados no cartório e no arquivo da Câmara da referida vila até aquela data. Resultam dessa investigação multidisciplinar as descrições de aspectos codicológicos e paleográficos do livro, assim como uma análise diplomática do documento. Do ponto de vista histórico, o conteúdo do texto dá uma amostra da produção documental e do arquivamento desses papéis na dita vila. O manuscrito, portanto, é um testemunho significativo para a história da escrita e da custódia de documentos em instituições como uma Câmara municipal e um cartório no Brasil do século XVIII.

Palavras-chave: Filologia; Codicologia; Paleografia; Diplomática; século XVIII.

1 Universidade de São Paulo (USP), São Paulo, São Paulo, Brasil; ivan.uhf@usp.br; https://orcid.org/0000-0001-5730-4329 


\title{
Book, quires, and single sheets: a philological study of registry and City Council archive inventory in Santana de Parnaíba (1764)
}

\begin{abstract}
This paper aims at presenting the philological study of a document registered onto the "Livro de Actas 1757 a 1764" written in Santana de Parnaiba, Brazil, entitled "Termo de emtregua do Cartorio desta villa [...]". In fact, the document, written on January 12 , 1764, functions as an inventory because it lists books and single sheets produced and/ or kept by the city's registry and the City Council archive of the referred town until that time. As results of this multidisciplinary investigation, we present the codicological and paleographical descriptions of the book, as well as a diplomatic analysis of the document. From a historical point of view, the document's content provides a picture of the documental production and archiving in that town. So, the manuscript is a significant testimony to the history of writing and document custody in institutions as a City Council and a registry in Eighteenth Century Brazil.
\end{abstract}

Keywords: Philology; Codicology, Paleography; Diplomatics; $18^{\text {th }}$ century.

\section{Considerações iniciais}

Este artigo se insere no âmbito dos estudos filológicos que tomam essa ciência como "uma configuração de habilidades acadêmicas voltadas à curadoria do texto histórico" (GUMBRECHT, 2003, p. 2, tradução nossa²). Nessa perspectiva, aplicamos o aparato teórico-metodológico de três ciências afins à Filologia, a saber, a Codicologia, a Paleografia e a Diplomática, ao estudo do documento "Termo de emtregua do Cartorio desta villa que faz o Ajudante Joaõ da Costa Sylva a Jozé Francysco Payva como nelle Se declara"3, lavrado a 12 de janeiro de 1764 pela Câmara de Santana de Parnaíba.

O trabalho objetiva apresentar o estudo filológico do referido "Termo de emtregua do Cartorio [...]", o qual se encontra lavrado no "Livro de Actas 1757 a 1764" de Santana de Parnaíba, Brasil. O documento, de fato, funciona como um inventário, pois contém listas de maços de papéis avulsos e de livros produzidos e/ou guardados no cartório e no arquivo da Câmara da vila até aquela data. Apresentamos, assim, por meio de uma investigação multidisciplinar, a descrição dos elementos que configuram o suporte material do texto, além de uma análise da estrutura diplomática do documento, análise esta que se configura como nosso objetivo específico. Do ponto de vista histórico, o conteúdo do texto dá uma amostra da produção documental e do arquivamento desses papéis na referida vila. O manuscrito, portanto, é um testemunho significativo para a

2 No original: "a configuration of scholarly skills geared toward historical text curatorship.".

$3 \mathrm{~A}$ transcrição de trechos do documento será conservadora no que se refere à grafia. 
história da escrita e da custódia de documentos em instituições como uma Câmara municipal e um cartório no Brasil do século XVIII.

Tal proposta justifica-se, em primeiro lugar, pela relevância, do ponto de vista filológico, de códices que servem de suporte para documentos da administração de vilas coloniais brasileiras. Exemplificando essa relevância, trabalhos como os de Ferreira (2008), Souza (2011) e Morais (2018) apresentam estudos sobre livros das Câmaras de Mogi das Cruzes-SP, Botucatu-SP e Jundiaí-SP, respectivamente. Em segundo lugar, o estudo filológico de um texto cujo teor é, especificamente, a guarda de livros e documentos avulsos em arquivos também se mostra pertinente. A análise de seus componentes materiais e de sua estruturação enquanto documento diplomático são de interesse não só para a Filologia, mas também para a História.

\section{Materiais e métodos: o "Livro de Actas" e como o abordamos pela Filologia}

Cumpre, agora, direcionarmos algumas palavras acerca do códice no qual o texto estudado foi lavrado. Antes, porém, discorremos sobre a abordagem teórico-metodológica escolhida. Para tanto, retomamos a definição de Filologia apresentada anteriormente. Ela traz em si algumas questões passíveis de maior esclarecimento.

Como apontado anteriormente, Gumbrecht (2003) afirma que a Filologia tem como objetivo a curadoria de textos históricos por meio de habilidades acadêmicas. A primeira questão que se coloca é a definição de curadoria. Ferreira (2016, p. 234-235) ilustra a aplicação do conceito de curadoria ao trabalho filológico. $\mathrm{O}$ autor associa a palavra latina curare ao significado de "tomar conta de" ou "administrar" e enumera usos comuns de "curadoria", citando sua utilização para se tratar dos cuidados com obras de arte e sua exibição, da administração de museus, da conservação e restauração de objetos e, já no campo do Direito, da administração dos interesses patrimoniais de inabilitado. Ao justapor os conceitos de curador e de filólogo, o autor conclui que:

Pese embora o fato de estas atividades serem substancialmente diferentes tanto entre si como em relação à filologia, é nossa contenção que, tal como em todas as atividades acima mencionadas a título de exemplo, também a filologia é uma atividade nos termos da qual o filólogo tem a seu cargo a tarefa de cuidar de algo, isto é, de uma parte, ou da totalidade, de patrimônio alheio, que, neste caso, é o texto criado por um determinado autor. (FERREIRA, 2016, p. 235).

Isso posto, notamos que o autor fecha o raciocínio no qual atribui à atividade filológica a função de curadoria ao afirmar que "na medida em que textos também podem ser obras de arte, e em que a função do filólogo é a de administrar textos, o filólogo é um curador textual" (FERREIRA, 2016, p. 237). 
O segundo ponto que nos parece importante é a própria definição de texto. Do ponto de vista da Filologia, o texto é formado por 3 níveis:

Em uma perspectiva filológica, o texto pode ser dividido em três diferentes níveis de exame: o nível material, o nível formal e o nível substancial. A matéria de um testemunho compõe-se de suas características físicas, tais como, o suporte material e as tintas. A forma abrange a roupagem paleográfica (forma e realização das letras, diacríticos, pontuação etc.) e gráfica (grafos, alógrafos, diacríticos, pontuação etc.) de um testemunho, assim como as repercussões do nível gráfico na representação fonética e morfológica de variantes históricas e dialetais das palavras. A substância reúne os níveis morfossintático, lexical e semântico de um testemunho. 0 estudo do texto a partir dessa tríplice divisão deve ser feito sempre a partir do pressuposto de que o texto (assim como seus testemunhos) é produto de um ambiente sócio-histórico e cultural determinado. (TOLEDO NETO, 2020, p. 192, nota 3).

Logo, quando efetuamos estudos filológicos, estamos, na verdade, manuseando um objeto tridimensional. Suas dimensões, mesmo que complementares e de limites bastante sutis, podem ser analisadas em separado de acordo com as especificações de cada pesquisa. O fato é que, no trabalho com textos escritos, seja de cunho filológico ou histórico, os três níveis devem ser compreendidos como partes fundamentais do objeto que se pretende estudar e, no caso específico do filólogo, editar.

Passamos, agora, às habilidades acadêmicas aplicadas nesta pesquisa e como elas atuam sobre os diferentes níveis do texto. Castro (1997, p. 605-606) lista, entre as principais disciplinas filológicas, a Paleografia e a Codicologia. Aqui, também utilizamos a Diplomática, pois ela, como as demais, encontra no texto escrito seu objeto de estudo.

As características codicológicas do livro que abriga o texto sob análise são exploradas por meio da adaptação de um roteiro de descrição elaborado por Cambraia (2005). Assim, aspectos referentes à trajetória do códice (confecção primitiva, local de utilização e custódias), sua composição intrínseca (características do suporte e organização dos cadernos) e suas características extrínsecas (tintas e instrumentos de escrita, organização da página e conteúdo) são apresentados de forma sucinta. Além disso, algumas características específicas do termo que analisamos aqui são apresentadas.

Itens relacionados ao nível formal do códice são abordados a partir de um estudo paleográfico. Logo, trazemos uma breve descrição da escrita que se materializa no "Livro de Actas 1757 a 1764". Como lidamos aqui com um livro escrito por diversos escrivães, damos especial atenção ao responsável pelo documento deste trabalho. 
Por fim, lançamos mão do aparato teórico-metodológico da Diplomática para o estudo da composição do texto que examinamos nesta pesquisa, uma vez que seu objeto de análise é a estrutura formal dos documentos enquanto registros de atos administrativos (BELLOTTO, 2002). E é a partir da análise diplomática que afirmamos que o "Termo de emtregua do Cartorio" tem, de fato, a função de inventário dos livros e papéis custodiados por instituições da vila de Santana de Parnaíba em janeiro de 1764.

\section{Aspectos codicológicos}

Como referimos anteriormente, o texto escrito é, do ponto de vista da Filologia, um objeto tridimensional. Assim, o estudo do nível material de um testemunho de determinado texto configura-se como importante etapa do trabalho filológico.

Livros como o que analisamos aqui têm sua materialidade concretizada em quatro etapas. A primeira diz respeito à sua confecção primitiva, que engloba a formação dos cadernos, sua junção por cosedura e encadernação ${ }^{4}$. A segunda etapa de sua configuração material concentra-se na foliação e na rubrica dos fólios, seguidas da redação dos termos de abertura e encerramento, muito comuns em livros utilizados em instituições jurídicoadministrativas como uma Câmara municipal do Brasil Colônia. Sua terceira fase da constituição é a sua utilização propriamente dita. Nela, escrevem-se os textos para os quais o livro fora destinado pela instituição ou por seu detentor particular. Por fim, vemos uma quarta fase de configuração de sua materialidade, a qual se refere às evidências de restauro, encontradas seja na encadernação seja em fólios isolados.

A análise dos componentes materiais ${ }^{5}$ que possibilitam a existência física do texto, assim como outros aspectos de sua produção material, tem ficado a cargo da Codicologia. García (2002, p. 19, tradução nossa ${ }^{6}$ ) aponta que a Codicologia é tema sobre o qual os especialistas não chegam a um acordo, nem sobre seu próprio nome, tampouco sobre seu conteúdo específico ${ }^{7}$. Sem nos alongarmos nessa questão, trazemos aqui uma descrição

4 Essa operação é precedida pela fabricação e trajetória do próprio papel, seu elemento constitutivo básico.

5 Spina (1977) fala em: a) matéria subjetiva, que é o suporte do texto; b) matéria aparente, no caso, as tintas usadas na produção do manuscrito; 3) matéria instrumental, que se refere ao instrumento que toca o suporte.

6 No original: "tema candente sobre el cual no se ponen de acuerdo los especialistas, ni en lo que atañe al nombre, ni en lo referente a su contenido específico.".

7 A autora (GARCÍA, 2002) elenca diferentes vertentes de trabalho da Codicologia. São elas a Codicologia descritiva (ou Codicografia), a Codicologia quantitativa e a Codicologia comparada. Além delas, são brevemente debatidas tanto uma tendência de pesquisas codicológicas cujos objetivos maiores são a cultura escrita, quanto uma corrente que se inspira na Semiótica em torno dos múltiplos significados dos componentes materiais dos manuscritos. 
sucinta dos principais elementos materiais do "Livro de Actas 1757 a 1764". Além disso, focamos em alguns pontos específicos do termo que estudamos mais detalhadamente.

O roteiro de descrição codicológica que utilizamos remonta a Cambraia (2005, p. 28). Seu excelente nível de aprofundamento abarca os mais diversos elementos materiais dos manuscritos. Complementarmente, propomos, em publicação recente, uma adaptação desse guia (SOUZA, 2020) a fim de estabelecermos uma análise codicológica mais bem direcionada ao tipo específico de livro manuscrito com o qual trabalhamos, a saber, o livro originalmente em branco, utilizado para registros manuscritos diversos.

Quadro 1. Descrição codicológica do livro

\begin{tabular}{|c|c|c|c|}
\hline Trajetória & Aspectos intrínsecos & $\begin{array}{l}\text { Aspectos } \\
\text { extrínsecos }\end{array}$ & $\begin{array}{l}\text { Evidências de } \\
\text { restauro }\end{array}$ \\
\hline $\begin{array}{l}\text { Papel italiano } \\
\text { Numerado e } \\
\text { rubricado em São } \\
\text { Paulo }^{10} \text {. }\end{array}$ & $\begin{array}{l}\text { Encadernação do } \\
\text { tipo contínua, de } \\
\text { couro marrom. }\end{array}$ & $\begin{array}{l}\text { Tinta ferrogálica, de } \\
\text { tonalidade marrom- } \\
\text { avermelhada. }\end{array}$ & \multirow{3}{*}{$\begin{array}{c}\text { Não há evidências } \\
\text { de restauro. O } \\
\text { códice se encontra } \\
\text { em bom estado de } \\
\text { conservação, exceto } \\
\text { pela encadernação, } \\
\text { pois a capa, cujo } \\
\text { papel que lhe serve } \\
\text { de preenchimento } \\
\text { foi cosido junto aos } \\
\text { nervos, não está } \\
\text { fixada ao corpo do } \\
\text { livro. }\end{array}$} \\
\hline $\begin{array}{c}\text { Usado em Santana } \\
\text { de Parnaíba, Brasil, } \\
\text { entre } 30 \text { de janeiro de } \\
1757 \text { e } 28 \text { de abril de } \\
1764 .\end{array}$ & $\begin{array}{l}\text { Suporte: papel bege. } \\
\text { Medidas: } 292 \mathrm{~mm} \mathrm{x} \\
\text { 200mm. }\end{array}$ & $\begin{array}{c}\text { Texto organizado } \\
\text { em uma coluna, sem } \\
\text { pautação. Mancha } \\
\text { de } 285 \text { mm x } 150 \\
\text { mm, em média, com } \\
32 \text { linhas por página, } \\
\text { em média. }\end{array}$ & \\
\hline $\begin{array}{l}\text { Encontra-se } \\
\text { custodiado pelo } \\
\text { Arquivo Público do } \\
\text { Estado de São Paulo, } \\
\text { sob o número de } \\
\text { ordem C06050. }\end{array}$ & $\begin{array}{c}242 \text { fólios: } 12 \\
\text { cadernos de } 10 \\
\text { bifólios (exceto os } \\
\text { cadernos } 3 \text { e } 12 \text {, } \\
\text { de } 16 \text { e } 5 \text { bifólios, } \\
\text { respectivamente). }\end{array}$ & $\begin{array}{c}\text { Conteúdo: } 244 \\
\text { documentos da } \\
\text { Câmara de Parnaíba, } \\
\text { além de } 6 \text { textos de } \\
\text { autoridades externas. }\end{array}$ & \\
\hline
\end{tabular}

Fonte: Elaboração própria

As quatro colunas do Quadro 1 acima sintetizam a descrição codicológica do "Livro de Actas 1757 a 1764". Na coluna Trajetória, apresentamos a origem do códice, além

8 A terminologia codicológica foi consultada em Briquet (1907), Faria e Pericão (2008), García (2002), Ostos, Pardo e Rodríguez (1997), assim como em https://vocabulaire.irht.cnrs.fr/vocab.htm.

9 Chegamos a essas informações pelo exame da marca d'água.

10 Os termos de abertura e de encerramento foram escritos em 27 de janeiro de 1757. 
de indicarmos os locais de sua preparação e de utilização, finalizando com a sua atual localização ${ }^{11}$. Na coluna Aspectos intrínsecos, vemos as características do suporte e a composição do livro. Em seguida, na coluna Aspectos extrínsecos, temos a descrição básica da tinta e a configuração das páginas. Por fım, na coluna Evidências de restauro, apontamos para o seu estado de conservação. Seguem-se duas imagens do códice.

Figura 1. A capa do códice

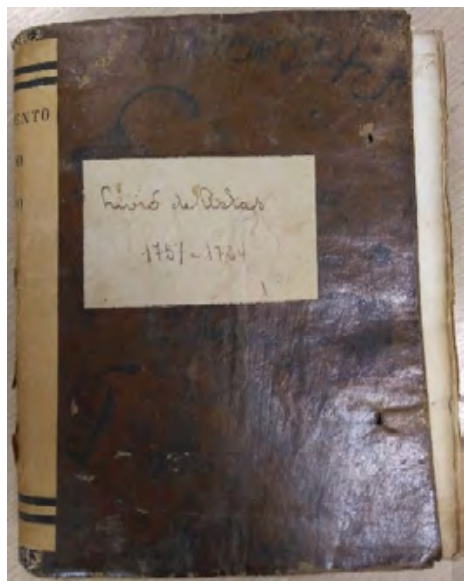

Fonte: Acervo próprio
Figura 2. Encadernação do códice

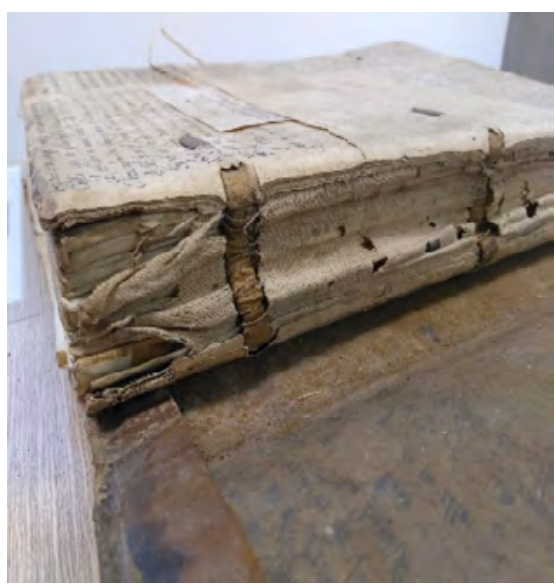

Fonte: Acervo próprio

\section{Aspectos paleográficos}

A Paleografia, ciência desenvolvida junto à Diplomática e que hoje goza de plena autonomia, auxilia tanto a Filologia quanto outras áreas do conhecimento, sobretudo a História. Dias e Bivar (2005, p. 12) apresentam propostas de conceituação de Paleografia que "gravitam em torno da ideia de leitura e transcrição de documentos manuscritos". Entre elas, se destaca a de Acioli (1994, p. 6), que afirma ser a Paleografia

[...] a ciência que lê e interpreta as formas gráficas antigas, determina o tempo e lugar em que foi redigido o manuscrito, anota os erros que possa conter o mesmo, com o fim de fornecer subsídios à História, à Filologia, ao Direito e a outras ciências que tenham a escrita como fonte de conhecimento.

Berwanger e Leal (2008, p. 15), por sua vez, listam conceitos de Paleografia. Afırmam que "em resumo, a Paleografia abrange a história da escrita, a evolução das letras, bem como

11 De acordo com Rodrigues (1961, p. 379), o livro que constitui o corpus deste trabalho está "na secção histórica do Departamento do Arquivo do Estado de São Paulo. Trata-se de documentação provavelmente inédita, recolhida àquela secção especializada em 8 de outubro de 1940". 
os instrumentos para escrever. Pode ser considerada arte ou ciência. É ciência na parte teórica. E arte na aplicação prática. Porém, acima de tudo, é uma técnica".

A abordagem paleográfica do livro aqui estudado baseia-se em Petrucci (2002). O autor, na esteira de Mallon (1952), afirma que a Paleografia deve ser a disciplina que se configura como uma verdadeira e própria História da cultura escrita e que, portanto, se ocupa da história, da produção, das características formais e dos usos sociais da escrita e dos testemunhos escritos de uma determinada sociedade, independentemente das técnicas e dos materiais adotados (PETRUCCI, 2002, s/p., tradução nossa ${ }^{12}$ ).

Para que se possa realizar a tarefa de uma Paleografia como a História da cultura escrita, o mesmo Petrucci indica os seguintes domínios da disciplina, ou melhor, as perguntas que devem ser feitas pelo pesquisador ao se deparar com o seu objeto de análise: 1) 0 quê?; 2) Quando?; 3) Onde?; 4) Como?; 5) Quem escreveu? e 6) Por que aquilo foi escrito? (PETRUCCl, 2002, s/p., tradução nossa ${ }^{13}$ ).

A primeira delas, o quê?, refere-se ao texto em si, no sentido de compreendê-lo como o objeto de uma prática consciente. A segunda questão, quando?, dirige-se à época em que o testemunho foi escrito. Onde? implica averiguar o local em que texto foi produzido. Responder à pergunta como? demanda a observação das técnicas e materiais utilizados naquele testemunho. Quem escreveu? é interrogação que vai além de nomear o escriba responsável por determinado texto, pois é necessário identificar o ambiente sociocultural ao qual ele pertencia e indagar qual a difusão social da escrita no seu tempo. Finalmente, a última pergunta, por quê?, busca não apenas a finalidade específica daquele texto, como também a finalidade ideológica e social de se escrever.

Desse modo, a análise paleográfica que realizamos neste trabalho permite extrair, da dimensão formal de uma amostragem dos documentos contidos no códice, elementos que possam reconstituir a história da cultura escrita na Câmara de Santana de Parnaíba. Na prática, a Paleografia nos possibilita responder: 1) O que está contido no códice? Ou como ele se caracteriza?; 2) Quando ou em que fase da escrita brasileira os textos foram produzidos?; 3) Onde foram escritos? Ou, mais precisamente, qual era a relação da Câmara com a escrita de modo geral?; 4) Como os textos foram escritos? Ou como eles se configuram nas páginas?; 5) Quem escreveu os textos? Ou, de fato, o que significava ser "escrivão da Câmara" no Brasil colonial? e; 6) Por que os textos foram produzidos? Ou, especificamente, para que serve o livro aqui analisado?

12 No original: "una disciplina che si configuri come una vera e propria storia della cultura scritta e che perciò si occupi della storia, della produzione, della caratterischique formali e degli usi sociali della scrittura e delle testimonianze scritte di una determinata società, indipendentemente della tecniche e da imateriali di vlta in volta adoperati.".

13 No original: "che cosa?; quando? dove?; come?; chi lo ha eseguito? perché quel testo è stato scritto?". 
Quadro 2. Descrição paleográfica

\begin{tabular}{|c|c|}
\hline Questão & Respostas \\
\hline $\begin{array}{l}\text { O que o livro } \\
\text { contém? }\end{array}$ & $\begin{array}{c}\text { No geral, termos de vereança }{ }^{14} \text { dos oficiais da Câmara vila de Santana de } \\
\text { Parnaíba. }\end{array}$ \\
\hline $\begin{array}{l}\text { Quando foi } \\
\text { escrito? }\end{array}$ & $\begin{array}{c}\text { Entre } 30 \text { de janeiro de } 1757 \text { e } 28 \text { de abril, ou seja, sua escrita situa-se no } \\
\text { período de surgimento das escritas nacionais. Tem influência dos modelos } \\
\text { italiano e inglês }{ }^{15} \text {. }\end{array}$ \\
\hline $\begin{array}{l}\text { Onde foi } \\
\text { escrito? }\end{array}$ & $\begin{array}{l}\text { Segundo os documentos que abriga, o livro foi escrito na "casa da Câmara } \\
\text { e conselho dela". As vilas representavam a municipalidade, o poder local } \\
\text { no Brasil Colônia }{ }^{16} \text {. Suas Câmaras tinham atuação administrativa, política } \\
\text { e judiciária }{ }^{17} \text {. Eram, assim, grandes produtoras de documentos avulsos e } \\
\text { livros de documentos }{ }^{18} \text {. }\end{array}$ \\
\hline $\begin{array}{l}\text { Como os } \\
\text { textos se } \\
\text { apresentam? }\end{array}$ & $\begin{array}{l}\text { Como já referido, os textos organizam-se em uma coluna, sem pautação. A } \\
\text { mancha mede } 285 \text { mm x } 150 \text { mm, em média, com } 32 \text { linhas por página, em } \\
\text { média. }\end{array}$ \\
\hline
\end{tabular}

14 A análise diplomática que se seguirá contém o detalhamento dos documentos contidos no livro.

15 Quanto à classificação da escrita contida no livro, seguimos Toledo Neto (2018, p. 303). 0 autor propõe a seguinte nomenclatura para as escritas que vigoraram em Portugal e no Brasil desde o Descobrimento: escrita gótica (subdividida em cortesã, processual e processual encadeada) e escrita humanística e seus subtipos (direita ou librária, cursiva, chanceleresca, bastarda e bastardilha, esta também conhecida como escrita nacional). Afirma, ainda, existirem tipos híbridos de escrita, que se caracterizam pela presença de traços distintivos de mais de um padrão. No caso do livro em apreço, a modalidade de escrita que observamos é a humanística inclinada, surgida no séc. XVI. Complementarmente, podemos afirmar que o livro apresenta duas variedades desse subtipo. Vemos traços tanto da inclinada italiana quanto da inclinada inglesa, ambas desenvolvidas a partir da segunda metade do séc. XVIII.

16 Zenha (1948) debate os pormenores do surgimento dos municípios brasileiros.

17 Sobre o papel das primeiras Câmaras municipais brasileiras, cf. Cortines Laxe (1885).

18 Segundo Chartier (2014, p. 28-29): "[...] o recurso à escrita desempenhou um papel essencial em diversas evoluções principais dentro das sociedades ocidentais. A primeira delas foi a construção de um estado baseado em justiça e finanças, que supõe a criação de burocracias, a constituição de arquivos e o desenvolvimento de comunicação administrativa e diplomática.". 


\begin{tabular}{|c|c|}
\hline $\begin{array}{c}\text { Quem os } \\
\text { escreveu? }\end{array}$ & $\begin{array}{c}\text { Os documentos foram escritos por } 4 \text { escrivães, os quais, além de servirem à } \\
\text { Câmara, também podiam exercer seu ofício em outras frentes } \\
\text { considerados oficiais, mas sim funcionários da } \text { Câmaram }^{20} \text {. }\end{array}$ \\
\hline $\begin{array}{c}\text { Para que serve } \\
\text { o Livro de } \\
\text { Actas? }\end{array}$ & $\begin{array}{c}\text { Os livros das Câmara serviam como testemunhos e provas dos atos dos } \\
\text { seus oficiais. Eram guardados em arcas e, quando necessário, consultados } \\
\text { e trasladados. }\end{array}$ \\
\hline
\end{tabular}

Fonte: Elaboração própria

Como apreendemos do Quadro 2 acima, um breve estudo paleográfico do "Livro de Actas 1757 a 1764" revela algumas questões relacionadas à sua história, o que inclui seu conteúdo sumário e sua apresentação formal. Incide, também, sobre pontos de sua função enquanto repositório de escrita oficial e relativamente pública da localidade onde foi utilizado. Seguem duas imagens que ilustram a sua descrição paleográfica.

Figura 3. Termo de abertura do livro

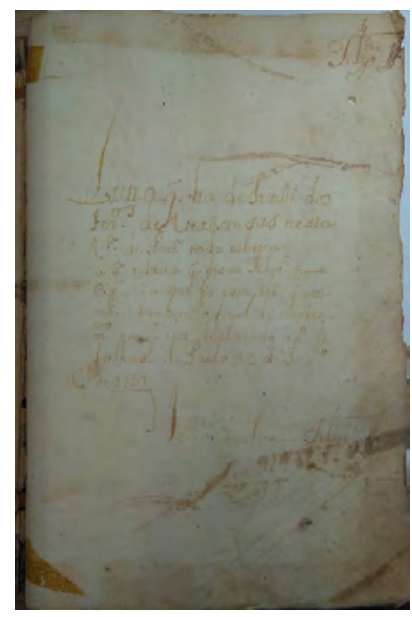

Fonte: Acervo próprio
Figura 4. Fólio $215 r$.

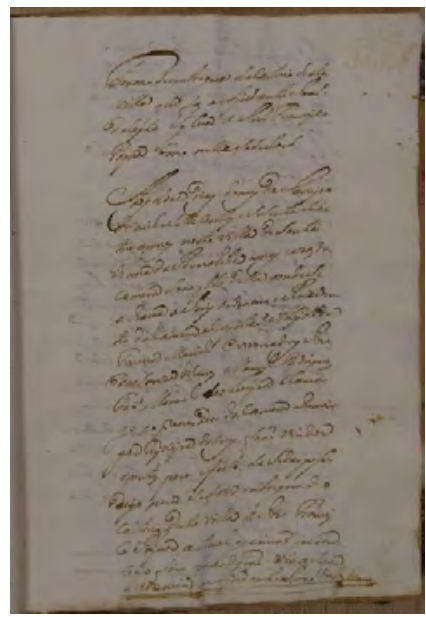

Fonte: Acervo próprio

\section{Resultados: análise diplomática do "Termo de emtregua do Cartorio"}

Seguem-se os resultados da análise diplomática, tanto do "Livro de Actas 1757 a 1764" como um todo quanto do documento central do artigo, o "Termo de emtregua do Cartorio".

19 Stumpf (2017) trabalha o prestígio social e algumas questões pecuniárias que envolviam o cargo de escrivão da Câmara na América portuguesa.

20 Fonseca (2016) esmiúça as atribuições dos escrivães das Câmaras portuguesas no Antigo Regime. A autora afirma, ainda, que tais funcionários, apesar de excluídos do governo, ao menos oficialmente, desempenhavam papéis da mais alta importância. 
Argumentamos que o referido termo serve de guarnição para um inventário dos livros e papéis avulsos custodiados pelo Cartório e pela Câmara de Parnaíba.

O "Livro de Actas 1757 a 1764", como referido anteriormente, contém um total de 242 fólios e 244 documentos ${ }^{21}$. Nesse conjunto, encontramos 225 termos, dos quais 153 são termos de vereança. Além dos termos, há autos, registros e traslados, como mostra a tabela 1 abaixo.

Tabela 1. Espécies documentais encontradas no "Livro de Actas 1757 a 1764"

\begin{tabular}{c|c}
\hline Espécie & Total \\
\hline Termo & 225 \\
\hline Traslado & 5 \\
\hline Registro & 5 \\
\hline Auto & 1 \\
\hline Indefinida & 8 \\
\hline TOTAL & $\mathbf{2 4 4}$ \\
\hline
\end{tabular}

Fonte: Elaboração própria

Spina (1977, p. 49) e Bellotto (2002, p. 39) tratam das partes fundamentais dos documentos diplomáticos, que são o protocolo inicial, o texto e o protocolo final. Cada uma dessas partes apresenta subdivisões de acordo com a espécie e o tipo documental. A análise diplomática do documento deste trabalho, que, no livro, se estende do fólio 215r. até o 220v., mostra a seguinte configuração:

21 Essa contagem não inclui os termos de abertura e de encerramento do livro, nem documentos de autoridades externas à Câmara, como vistos de correição produzidos por corregedores. 
Quadro 3. Partes do documento, segundo a Diplomática

\begin{tabular}{|c|c|c|}
\hline Item & Subitem & Trecho $^{22}$ \\
\hline \multirow{4}{*}{ Protocolo inicial } & Título & $\begin{array}{c}\text { "215r.\| Termo de emtregua do Cartorio desta villa que fas o } \\
\text { Ajudante loaõ da Costa Sylva a losé Francisco Pajva Como } \\
\text { nelle se declará }\end{array}$ \\
\hline & $\begin{array}{l}\text { Datação } \\
\text { cronológica }\end{array}$ & $\begin{array}{l}\text { Aos doze dias do mes de lanejro de mil e SetteCentos e } \\
\text { SeSenta e Coatro annos }\end{array}$ \\
\hline & $\begin{array}{l}\text { Datação } \\
\text { tópica }\end{array}$ & $\begin{array}{c}\text { nesta villa de Santa Anna de Parnahiba em as cazas da } \\
\text { Camera e Conseylho della }\end{array}$ \\
\hline & $\begin{array}{l}\text { Nomeação } \\
\text { dos } \\
\text { presentes }\end{array}$ & $\begin{array}{c}\text { aonde Se achava o luis ordinario e Prezidente da Camera o } \\
\text { Capitaõ Alejxo da Fonceca Maciel E os vereadores loze de } \\
\text { Souza Nunes Manoel Rodrigues Faõ Manoel de oLivejva } \\
\text { Camargo e o procurador da Camera Domingos de Tejxejra } \\
\text { da Crus }\end{array}$ \\
\hline \multirow{4}{*}{ Texto } & Preâmbulo & $\begin{array}{l}\text { foraõ vindos e juntos pera efeito de Se dar posse digo pera } \\
\text { Se fazer emtregua do Cartorio desta villa a loze Francisco } \\
\text { Pajva autual escrivaõ pera cujo fis mandaraõ vir a Sua } \\
\text { prezencia o Ajudante Ioaõ da Costa Sylva ||215v.|| |loaõ da } \\
\text { Costa Sylval que havia Servido o dito officio }\end{array}$ \\
\hline & Exposição & $\begin{array}{c}\text { e pella rezaõ de naõ ter çe passado termo de emtregua dos } \\
\text { papeis do dito Cartorio }\end{array}$ \\
\hline & Dispositivo & $\begin{array}{c}\text { o mandaraõ agora passar e de Como os papeis que Se } \\
\text { acharaõ abaixo Se declaraõ e Saõ os Seguintes (...). ||219r.|| } \\
\text { Papeis que Se achavaõ no Arquivo da Caza da Camera } \\
\text { aonde nelle ficavaõ e Saõ os Seguintes (...). }\end{array}$ \\
\hline & $\begin{array}{l}\text { Cláusulas } \\
\text { finais }\end{array}$ & $\begin{array}{c}\text { ॥220r.|| Declaro que o Cartorio me foi emtregue a mim } \\
\text { escrivaõ pello luis ordinario e Prezidente da Camera o } \\
\text { Capitaõ Alejxo da Fonceca Maciel por virtude de aCordo } \\
\text { que Consta neste Livro a folha } 214 \text { Cujo aCordo Se fes } \\
\text { nesta Camera pellos offiçiais della e o dizer eu escrivaõ } \\
\text { que o dito Cartorio \|220v.\| ICartoriol me fora entregue em } \\
\text { prezençia dos officiais da Camera foi engano meo pois Só } \\
\text { perante elles Se me entregou os papeis e livros emtregues } \\
\text { a Camera }\end{array}$ \\
\hline \multirow[t]{2}{*}{ Protocolo final } & Subscrição & $\begin{array}{l}\text { e por passar na verdade faço esta declaraçaõ per mim } \\
\text { aSignada e passo na verdade o referido e me Asignej Eu } \\
\text { loze Francisco Pajva escrivaõ que a Escrevj e aSignej }\end{array}$ \\
\hline & Precação & Ioze Francisco Pajva \\
\hline
\end{tabular}

Fonte: Elaboração própria

22 Como afirmado anteriormente, a transcrição de trechos do documento é conservadora quanto à grafia. 
O quadro 3 mostra as partes fundamentais do documento. A seguir, trataremos com mais detalhes o subitem Dispositivo, o qual, segundo Bellotto (2002, p. 40), é "a substância do ato, seu 'assunto' propriamente dito". É nesse ponto que o escrivão faz o inventário dos "papéis" a serem entregues ao seu novo custodiador.

No que se refere ao dispositivo do documento, cujo início localiza-se no fólio $215 \mathrm{v}$. e segue até o 220r., podemos dividi-lo em duas partes: num primeiro momento, como exposto no título do texto e no próprio dispositivo, o escrivão faz a listagem dos itens pertencentes ao Cartório da vila. A tabela 2 a seguir sintetiza o conteúdo listado pelo escrivão. Temos, assim, a primeira parte do inventário.

Tabela 2. Inventário dos "papéis" do Cartório

\begin{tabular}{c|c|c}
\hline \multicolumn{1}{c|}{ Item $^{23}$} & Volumes & $\begin{array}{c}\text { Total de } \\
\text { documentos }\end{array}$ \\
\hline Maços de devassas & 3 & 231 \\
\hline Livros de rol de culpados & 1 & $?$ \\
\hline Livros de autos de querelas & 1 & $?$ \\
\hline Livros de sumários de querelas & 2 & $?$ \\
\hline Autos crimes & $?$ & 10 \\
\hline Livros de notas & 65 & $?$ \\
\hline Maços de protocolos de audiências de juízes ordinários e almotacéis & 1 & $?$ \\
\hline Maços de libelos crimes e autos de agravo & 1 & 29 \\
\hline Libelos & 10 & 127 \\
\hline Ações de dez dias & $?$ & 565 \\
\hline Ações de alma & $?$ & 235 \\
\hline Execuções & $?$ & 242 \\
\hline Coimas & $?$ & 6 \\
\hline Autos de medição de terras & $?$ & 14 \\
\hline Inventários & $?$ & 10 \\
\hline Maços de inquirições & 3 & 165 \\
\hline Maços de embargos e agravos & 3 & 287 \\
\hline Maços de justificações & 3 & 367 \\
\hline Maços de papéis avulsos & 3 & $?$ \\
\hline Livros de registros de testamentos & 1 & $?$ \\
\hline & & $?$ \\
\hline
\end{tabular}

Fonte: Elaboração própria

23 Para as listas de nossa autoria, optamos por modernizar a grafia das palavras. 
Vemos as denominações "Massos" e "Livros", que são contabilizadas na coluna Volumes. Julgamos serem documentos avulsos aqueles que não apresentam nenhuma daquelas categorizações. Quando o número de volumes ou de documentos avulsos não tiver sido especificado pelo escrivão, indicamos com o ponto de interrogação (?).

Na sequência, o escrivão lista os "papéis" do "Arquivo da Caza da Camara". Encontramos, além de "Massos" e "Livros", a categorização Caderno. A tabela 3 a seguir mostra o conteúdo dessa parte do inventário. Novamente, o ponto de interrogação (?) indica que o número de volumes ou de documentos avulsos não foi especificado.

Tabela 3. Inventário dos "papéis" do Arquivo da Câmara

\begin{tabular}{|c|c|c|}
\hline Item ${ }^{24}$ & Volumes & Total de documentos \\
\hline Livros de registros & 5 & $?$ \\
\hline Livro de eleições & 2 & $?$ \\
\hline Livros de contas dos corregedores da comarca & 1 & $?$ \\
\hline Livros de receitas e despesas & 4 & $?$ \\
\hline Livros de rendimentos & 1 & $?$ \\
\hline Cadernos de fianças & 1 & $?$ \\
\hline Livros de fornos & 1 & $?$ \\
\hline Livros de arrematações & 1 & $?$ \\
\hline Livros de provimentos & 1 & $?$ \\
\hline Livros de registro de licenças & 1 & $?$ \\
\hline Livros de mandados e de despesas & 1 & $?$ \\
\hline Livros de correições de almotacéis e oficiais da Câmara & 1 & $?$ \\
\hline Livros de vereança & 18 & $?$ \\
\hline Livros de assento dos procuradores & 1 & $?$ \\
\hline Maços de cartas escritas e recebidas & 1 & 52 \\
\hline Autos de agravo & $?$ & $?$ \\
\hline
\end{tabular}

Fonte: Elaboração própria

Como podemos ver na tabela 3 acima, apenas o Maço de cartas apresenta a quantidade exata de documentos que abriga. Os demais itens são apresentados somente no que se refere aos volumes. Não há nenhuma especificação no item Autos de agravo. O escrivão trata desses documentos no plural, mas não indica a sua quantidade.

24 Cf. nota anterior. 
A partir do exposto, podemos debater a formatação do documento. Muito embora seu título traga a especificação tipológica termo de entrega do cartório, sua parte principal, o dispositivo, revela um inventário. De fato, dois inventários: o do cartório e o do Arquivo da Câmara. Essa parte nuclear do texto se estende por 10 das 12 páginas do documento, ocupando (da linha 30 até a linha 257). As demais divisões do documento, tanto o protocolo inicial quanto o final, servem para emoldurar o que apresenta mais valor e importância naquele ato administrativo: a devida enumeração do que se entregava ao novo escrivão da localidade.

\section{Considerações finais}

Este artigo buscou efetivar a justaposição de ciências afıns à Filologia com o objetivo de pôr em prática o que chamamos de curadoria filológica do documento. Tal iniciativa permeia os cuidados com a descrição e a análise dos diferentes níveis de um texto escrito. No caso, trabalhamos com um termo escrito na Câmara de Santana de Parnaíba. Nosso objetivo foi comprovar que sua função principal era a produção de um inventário de livros e papéis avulsos produzidos e/ou guardados na referida vila.

Por meio de estudos codicológicos e paleográficos acerca do códice como um todo, pudemos resgatar informações sobre a origem material do "Livro de Actas 1757 a 1764" e caracterizar sua escrita. Ficou evidente que se trata de um códice valioso para estudos filológicos, linguísticos e históricos. Sua estrutura material revela procedimentos de confecção de livros em branco largamente utilizados em instituições administrativas até inícios do séc. XX. Seus textos, de modo geral, nos remetem a práticas de escrita e de produção documental vigentes no século XVIII.

Finalmente, o estudo diplomático indica a funcionalidade específica do documento em apreço. Sua estruturação formal na espécie termo emoldura um detalhado inventário. A referida entrega do cartório e do arquivo da Câmara ao novo escrivão fica em segundo plano, pois o valor documental dos papéis listados se sobressai.

\section{REFERÊNCIAS}

ACIOLI, V. L. C. A escrita no Brasil colônia: um guia para leitura de documentos manuscritos. Recife: EDUFPE; FUNDAJ; Massangana, 1994.

BELLOTTO, H. L. Como fazer análise diplomática e análise tipológica de documento de arquivo. São Paulo: Arquivo do Estado, Imprensa Oficial, 2002.

BERWANGER, A. R.; LEAL, J. E. F. Noções de paleografia e de diplomática. 3. ed. rev. e ampl. Santa Maria: Editora UFSM, 2008. 
BRIQUET, C. Les filigranes. Genebra, 1907. 4 vols.

CAMBRAIA, C. N. Introdução à crítica textual. São Paulo: Martins Fontes, 2005.

CASTRO, I. Filologia. Biblos: Enciclopédia Verbo das Literaturas de Língua Portuguesa. v. 2. Lisboa: Verbo, 1997.

CHARTIER, R. A mão do autor e a mente do editor. Tradução Roger Schlesinger. São Paulo: Editora UNESP, 2014.

CORTINES LAXE, J. B. Regimento das Câmaras Municipais ou Lei de $7^{\circ}$ de outubro de 1828. 2. ed. Rio de Janeiro: B. L. Garnier-Livreiro-editor, 1885.

DIAS, M. M.; BIVAR, V. dos S. B. Paleografia para o período colonial. In: SAMARA, E. de M. (org.). Paleografia e fontes do período colonial brasileiro. São Paulo: Humanitas/FFLCH/ USP, 2005. p. 11-38.

FARIA, M. I.; PERICÃO, M. da G. Dicionário do livro: da escrita ao livro eletrônico. São Paulo: Editora da Universidade de São Paulo, 2008.

FERREIRA, A. H. Atas da vereança de Mogi das Cruzes do século XVII (1612 a 1692): edição semidiplomática, glossário e descrição dos manuscritos. 2008. Dissertação (Mestrado em Filologia e Língua Portuguesa) - Faculdade de Filosofia, Letras e Ciências Humanas, Universidade de São Paulo, São Paulo, 2008.

FERREIRA, P. T. Filologia como curadoria: o caso Pessoa. Filologia e linguística portuguesa, São Paulo, v. 18, n. 2, p. 231-262, 2016. Disponível em: http://www.revistas. usp.br/flp/article/view/110219/120237. Acesso em: 11 ago. 2020.

FONSECA, T. O funcionalismo camarário no Antigo Regime. Sociologia e práticas administrativas. In: CUNHA, M. S. da; FONSECA, T. (org.). Os municípios no Portugal moderno - Dos forais manuelinos às reformas liberais. Évora: Publicações do Cidehus/Edições Colibri, 2016. p. 73-86. Disponível em: https://books.openedition.org/ cidehus/1112. Acesso em: 27 ago. 2020.

GARCÍA, E. R. Introducción a la codicología. Madrid: Fundación Germán Sánchez Ruipérez, 2002. 
GUMBRECHT, H. U. The Powers of Philology: Dynamics of Textual Scholarship. Champaign: University of Illinois Press, 2003.

MALLON, J. Paleographie romaine. Madrid: Instituto Antonio Nebrija de Filologia, 1952.

MORAIS, K. C. de. "Damos aos suplicantes os chãos que pede": edição fac-similar e semidiplomática e estudo do manuscrito Cartas de Datas de Jundiaí do século XVII. 2018. Dissertação (Mestrado em Filologia e Língua Portuguesa) - Faculdade de Filosofia, Letras e Ciências Humanas, Universidade de São Paulo, São Paulo, 2018.

OSTOS, P.; PARDO, M. L.; RODRÍGUEZ, E. E. Vocabulario de codicología. Madrid: Editorial Arco/Libros, 1997.

PETRUCCI, A. Prima lezione di paleografia. Bari: Editori Laterza, 2002 (edicione digitale: giugno, 2015). Disponível em: https://bit.ly/3r7k5Xv. Acesso em: 21 ago. 2020.

RODRIGUES, M. R. da C. Relação de 134 Códices valiosos para uma eventual história local de Santana do Parnaíba (1660-1932). Revista de História, n. 48, 4º trim. 1961. Disponível em: https://www.revistas.usp.br/revhistoria/article/view/121542/118429. Acesso em: 21 ago. 2020.

SOUZA, I. D. de. Atas da Câmara de Botucatu, SP (1858-59): edição e estudo. 2011. Dissertação (Mestrado em Filologia e Língua Portuguesa) - Faculdade de Filosofia, Letras e Ciências Humanas, Universidade de São Paulo, São Paulo, 2011.

SOUZA, I. D. de. Livros da Câmara Municipal de Santana de Parnaíba (sécs. XVII e XVIII): estudo codicológico. In: FACHIN, P. R. M.; MONTE, V. M. do. Pesquisas em Andamento: caminhos pela filologia e pela história e historiografia do português [recurso eletrônico]. São Paulo: FFLCH, 2020. DOI: 10.11606/9786587621104

SPINA, S. Introdução à edótica: crítica textual. São Paulo: Cultrix/EDUSP, 1977.

STUMPF, R. Dos homens que serviam entre papéis e letras - Escrivães das câmaras na América portuguesa. Nuevo Mundo Mundos Nuevos [Online], Débats, 2017. Disponível em: http://journals.openedition.org/nuevomundo/71379. Acesso em: 26 ago. 2020.

TOLEDO NETO, S. de A. Um caminho de retorno como base: proposta de normas de transcrição para textos manuscritos do passado. Travessias Interativas. São Cristóvão (SE), v. 10, n. 20, p. 192-208, jan./jun. 2020. Disponível em https://seer.ufs.br/index.php/ Travessias/article/view/13959/10679. Acesso em: 20 ago. 2020. 
TOLEDO NETO, S. de A. Datação e localização dos tipos de escrita: informações relevantes para a crítica textual? In: LOSE, A. D.; SOUZA, A. S. de (org.). Paleografia e suas interfaces. Salvador: Memória \& Arte, 2018.

ZENHA, E. O Município no Brasil (1532-1700). São Paulo: Instituto Progresso Editorial, 1948. 